\title{
Forms of Machines, Forms of Movement
}

\author{
Benoît Turquety
}

for Hadrien

\section{Fac-similes}

In a documentary produced in 1996-1997, American filmmaker Stan Brakhage, who spent much of his life painting and scratching film, stated that

One of the major things in film is that you have 24 beats in a second, or 16 beats or whatever speed the projector is running at. It is a medium that has a base beat, that is intrinsically baroque. And aesthetically speaking, it's just appalling to me to try to watch, for example, as I did, Eisenstein's Battleship Potemkin on video: it dulls all the rhythm of the editing. Because video looks, in comparison to the sharp, hard clarities of snapping individual frames, and what that produces at the cut, video looks like a pudding, that's virtually uncuttable, like a jello. It's all ashake with itself. And furthermore, as a colorist, it doesn't interest me, because it is whatever color anyone sets their receptor to. It has no fixed color. ${ }^{1}$

Each optical machine produces a specific mode of perception. Canadian filmmaker Norman McLaren also devoted an essential part of his work to research on the material of film itself, making films with or without camera through all kinds of methods, drawing, painting, scratching film, developing a reflection on what a film frame is and what happens in the interval between two images. Yet today his work is distributed by the National Film Board of Canada only in digital format, and such prestigious institutions as the Centre Pompidou in Paris project it that way - even as the compression of digital files required by their transfer on DVD pretty much abolishes the fundamental cell that is the single frame. 
Beyond these singular cases, the discontinuation of film as a medium to the benefit of digital media raises a number of issues at the moment. As it happens, these issues - originating in equal parts in audiences, critics and professionals dealing with a transformation of their tools, methods and general professional structures - start from a common premise: "one can barely tell the difference" between film and digital. The stakes of the transition between formats are mostly economic, occasionally practical, sometimes tied to sporadic differences in rendering, but in the end these are just moving photographic images - or so the assumption goes. Still, differences are crucial because the modes of production of these moving images lead to singular modes of perception, at a level rarely explored by analysis. The transition between media should be thought in the context of the "facsimile" as developed by Erwin Panofsky in a 1930 text:

[...] I wish and I hope that we will learn to improve and will continue to make "better" facsimile reproductions. It is because of these advances, and not despite them, that we will be increasingly adept at distinguishing the original from its facsimile reproduction. Furthermore, it is because of these advances, and not despite them, that we will increasingly regard facsimile reproductions with benefit and, even, enjoyment. ${ }^{2}$

The film watched in video is a facsimile of the original, a certain amount of "information" or characteristics of which it conveys, while some others disappear or undergo transformation. At any rate, it may not be defined as anything but a facsimile. ${ }^{3}$ Still, as Panofsky also points out, ${ }^{4}$ the nature and the scope of transformations remain to be evaluated for each work according to the degree of dependence of form on the material that embodies it. If we are to grasp what is at stake in this shift to digital, we need to understand and identify with accuracy the specificities of each machine and the viewing conditions it produces, and more generally expand this research to the history of dispositives of moving or of animated images - if these two notions do in fact refer to the same thing. This necessity was already spelled out by Jonathan Crary in his Techniques of the Observer (1990):

2 Erwin Panofsky, “Original und Faksimilereproduktion," Der Kreis. Zeitschrift für künstlerische Kultur (Spring 1930), available in English as "Original and Facsimile Reproduction," trans. Timothy Grundy, in Res. Anthropology and Aesthetics 57-58 (Spring-Autumn 2011): 337.

3 On this question and some of its implications for film studies, see the "Statement on the Use of Video in the Classroom" issued by the Society for Cinema Studies Task Force on Film Integrity, chaired by John Belton, Cinema Journal 30.4 (Summer 1991): 3-6.

4 Panofsky, “Original und Faksimilereproduktion": 337-38. 
$[\ldots]$ there is a tendency to conflate all optical devices in the nineteenth century as equally implicated in a vague collective drive to higher and higher standards of verisimilitude. Such an approach often ignores the conceptual and historical singularities of each device. ${ }^{5}$

Indeed, each machine involves in its very form a certain conception of its task, its ends and the means to achieve them, and in return, these means have consequences on the nature of the result. Each machine is thus potentially rich in theoretical lessons, be it through visual experience or through an epistemological reflection on the historical conditions of its conception.

Taking into account the technical level, machines and practices, from the camera to the script, from flatbed editing machines to the architecture of movie theaters, is rather rare in film theory (except in archival literature, for some aspects ${ }^{6}$ ) and raises specific methodological problems. The technological analysis of machines should be confronted with their production, with the discourses around them and with their concrete uses, whether dominant or marginal. When it comes to the evolution of technical objects themselves, it should also relate the respective logics of conception, usage and industrialization.

\section{The Form of a Machine: A Surprising Zoetrope}

The clinical study of a singular case, based on some important technical aspects in the representation of moving images shared by nineteenthcentury optical toys and the first cinematographic machines, will help shed light on a few issues.

Charles Francis Jenkins was one of the first important "pioneers" in the technologies of cinema and television. With Thomas Armat, he notably invented a projector, the Phantoscope, which was presented to the public in September 1895. In 1916, he was also the founder of one of the most impor-

5 Jonathan Crary, Techniques of the Observer: On Vision and Modernity in the Nineteenth Century (Cambridge: MIT Press, 1990). Crary unfortunately does not apply this principle with much precision, contenting himself with a general scheme of the camera obscura without distinguishing its various historical concretizations. Also, when it comes to the nineteenth century, he only particularizes the stereoscope, the kaleidoscope and devices for the analysis and the synthesis of movement, merged into a third category.

6 Among these, I will mention the evolution of mediums (nitrate film, acetate cellulose film), the chemistry of coloring processes or "natural" colors, projection speeds, aspect ratios, etc. See for instance Paolo Cherchi Usai, Silent Cinema: An Introduction (London: BFI, 200o). 
tant professional institutions of technicians, in film and later in television, the Society of Motion Picture Engineers. ${ }^{7}$ The organization immediately published a periodical, ${ }^{8}$ for which Jenkins himself wrote one of the earliest historical pieces in October 1920, "History of the Motion Picture." The contribution begins with what was already becoming common practice: going back to the dawn of time to search for a lost origin of cinema and trace it in more or less relevant and even improbable phenomena. According to Jenkins, the "first motion picture mechanism we have any record of" "was the Zoetrope, whose origin he dated back to Lucretius. He briefly describes the optical toy that "you all doubtless well know," presenting an illustration without commenting on it. ${ }^{10}$ However, the interest of the illustration (Fig. 1) is that the machine it features is not at all a "common specimen" of the Zoetrope, to use the language of taxonomists.

The Zoetrope is an optical toy invented independently in 1834 by William George Horner (Great Britain) and Simon von Stampfer (Austria), both mathematicians (that fact alone deserves a closer look). For reasons that remain to be identified, it was commercialized only in 1867 . The Zoetrope comprises a cylinder with slits cut at regular intervals, which can rotate around its axis; within the cylinder, a sequence of images placed between the slits present a series of patterns describing a given subject in movement. When the cylinder is spun and the viewer looks through the slits, the images in the series appear to move.

Yet the Zoetrope presented in Jenkins's article involves two unusual characteristics.

First, its cylinder is oriented vertically, which was extremely rare. In principle, the cylinder in a Zoetrope is horizontal, primarily because the strips of images have to be easy to change and should fit the edges of the cylinder perfectly. In a spinning vertical cylinder, the strips risk falling off or have to be fastened carefully, which complicates the operation with no apparent benefit. Second, one might add that there is a logic

7 Today the organization is called the SMPTE, or Society of Motion Picture and Television Engineers.

8 First titled Transactions of the Society of Motion Picture Engineers, it later became the Journal of the SMPE, then the Journal of the SMPTE.

9 Charles Francis Jenkins, "History of the Motion Picture," Transactions of the Society of Motion Picture Engineers (Oct. 1920), in A Technological History of Motion Pictures and Television: An Anthology from the Pages of The Journal of the Society of Motion Picture and Television Engineers, ed. Raymond Fielding (Berkeley, Los Angeles: University of California Press, 1967) 1.

10 Jenkins, "History of the Motion Picture," in Fielding, A Technological History of Motion Pictures and Television 1. 


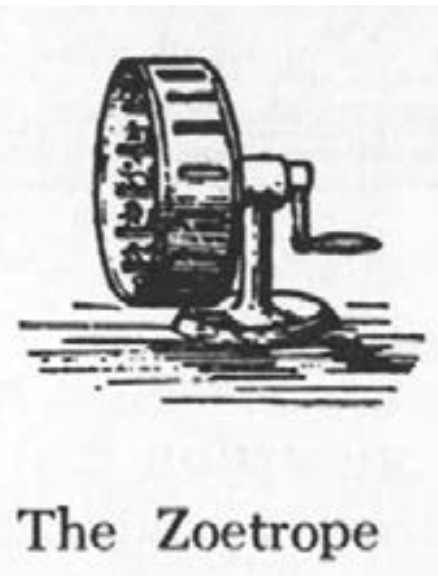

Fig. 1. "The Zoetrope," in Charles Francis Jenkins, "History of the Motion Picture," Transactions of the SMPE, (October 1920): 37.

to the horizontal cylinder tied to the fact that most of the movements presented - typically, the gallop of a horse - are horizontal. This is in no way a technical constraint (horizontal movement can be represented on a strip running vertically), but rather a matter of conceptual coherence. The possibility of placing the cylinder vertically appeared in one model only, a late variant developed by Ottomar Anschütz from Germany around 1890 under the name of Tachyscope or Schnellseher (Fig. 2) and featuring a series of phototypes (Anschütz had come to these matters through an initial interest in chronophotography). The cylinder could be placed horizontally or vertically, depending on the band to be viewed. The copy preserved at the Cinémathèque française comes with a box of ten strips, two of which only run vertically. ${ }^{11}$ This choice has to do with the fact that some subjects required a wider rather than a taller frame: the strip taken vertically thus made it possible to arrange more images. It was also the result of an insight described in Anschütz's December 1891 German patent:

The vertical position of the cylinder results in a peculiar arrangement of images, which proves important in the representation of discontinuous and non-periodical processes, among other examples (a horse jumping over a fence, etc.). In this case, the constant vision of several animated 


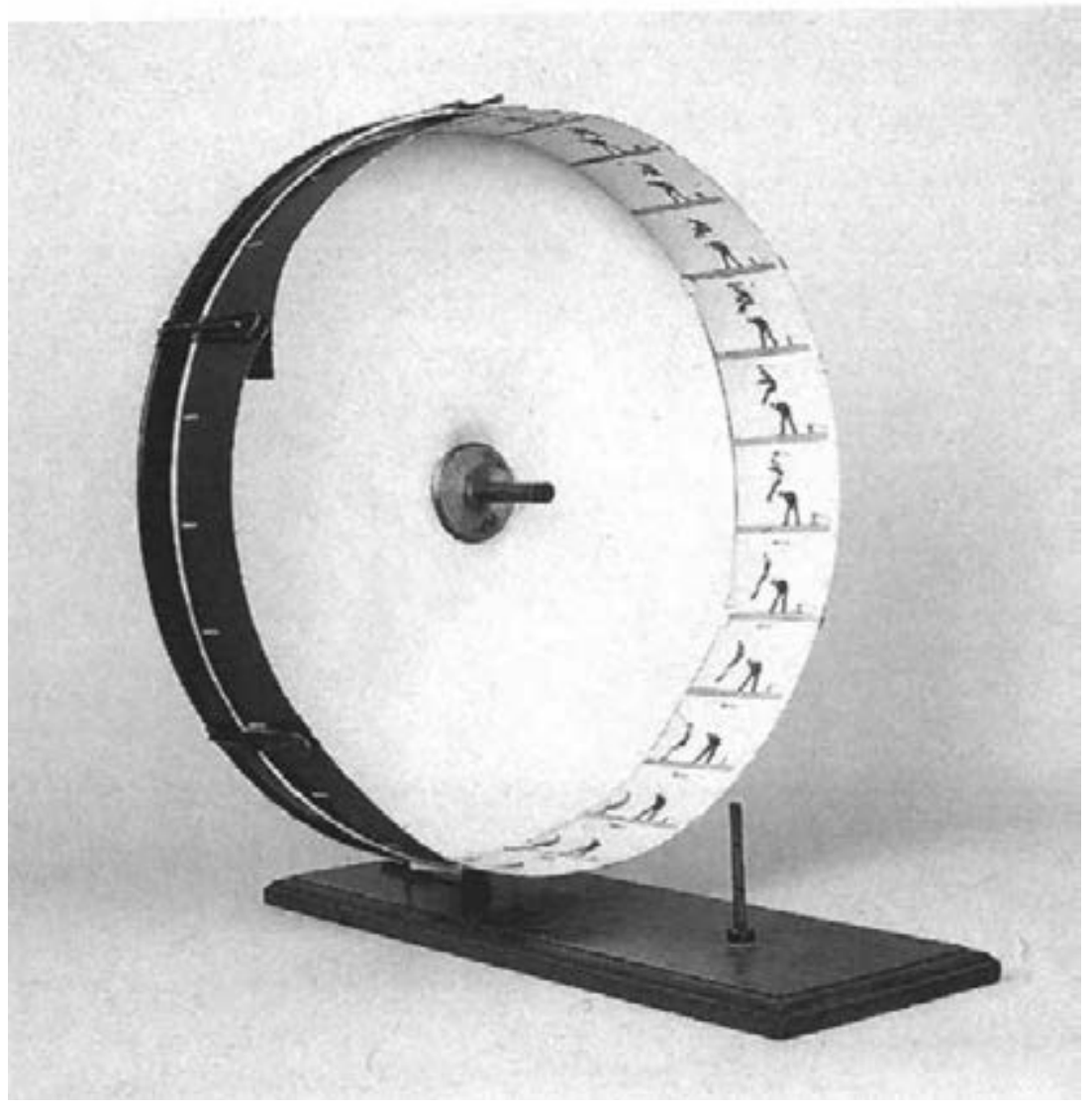

Fig. 2. Tachyscope, or Schnellseher, Ottomar Anschütz, after 1890, collection of the Cinémathèque française (vertical layout).

images at different stages of the movement, as happens with common stroboscopic devices, often proves a distraction for the eye. It is much preferable to see the object move across the field of vision at its natural speed, and this can be done in the most simple way by positioning the cylinder vertically. In this way, images representing a single, differentiated action are no longer found side by side, but one on top of the other. ${ }^{12}$

Mentioning the flaws noted in the use of "usual" devices and describing the solution brought to them are common developments in the rhetoric of

12 Ottomar Anschütz, German patent n 60285, 19 Dec. 1891. Translator's note: this an English translation of the author's own translation from the German to the French. 
patents. Anschütz articulates a technical thought on the form to be given to the machine with a series of observations that belong in the psychology of perception. Like the Phenakistiscope, to which I will return, the Zoetrope presents several animated images to the spectator at the same time. This effect is typically considered a fundamental given of the device, especially for the Phenakistiscope, and as an even more admirable aspect of the device in question. In "Morale du joujou," Baudelaire thus wrote:

The speed of rotation transforms the twenty openings into a single circular opening through which you watch twenty dancing figures reflected in the glass - all exactly the same and executing the same movements with a fantastic precision. Each little figure has availed itself of the nineteen others. $^{13}$

The cylindrical form of the Zoetrope transforms this effect to some degree, since the perspective of the viewer results in singling out a limited number of animated figures, one of which is central, others more lateral, being distorted by the drum. Anschütz was to confirm this evolution and reinforce it, in relation to a more general observation: some types of movements, "discontinuous and non-periodical processes," have as their central characteristic not to repeat themselves. It is thus disturbing - visually if you will, but the criterion is cognitive - to see them occur several times simultaneously. Placing these parasitic images vertically rather than before and after horizontally thus represents a gain in comfort and solves the problem. Indeed, for Anschütz, the machine does not have as its goal to animate images, but to observe one animated image and one only, which is a rather original conception. Besides, the criterion of non-continuity and non-periodicity, which is the base for the importance of the uniqueness of the image as spectacle, is in the end nothing else than a criterion of narrativity: for the German inventor, when the animated image becomes the source for a narrative (something unique occurs and breaks circularity), it becomes imperative for that image to be the only spectacle and the device has to be modified accordingly. Ultimately, the form of the movement to be depicted commands the form of the machine.

The Tachyscope, it should be noted, did not have a crank; and the crank happens to be the other characteristic distinguishing the machine featured 
in the illustration of Jenkins's article from the zootropus vulgaris. Zoetropes with cranks were extremely rare; most of them seem to have been moved directly by hand. When they happened to have cranks, these did not have that shape at all: they were smaller, placed differently, etc.

Two questions arise here:

- First, why did so few Zoetropes use a crank? And why a certain form of crank rather than another? I will return to this aspect.

- Second, why did Jenkins's article represent the Zoetrope in this odd form, one which I believe may not even have actually existed?

In fact, the drawing is entirely teleological; what it represents is not really a Zoetrope but a "pre-camera" or a "pre-projector," just as some talk of "pre-cinema." Until the 1920s, a typical film camera or projector featured a crank configured similarly, with the film strip running vertically. This warrants a few observations.

First, in history, teleology may sometimes be found in unexpected places. Then, in 1920, the members of the prestigious Society of Motion Picture Engineers already seemed to have forgotten - contrary to what Jenkins wrote - what kind of machine the Zoetrope actually was, or already seemed to see it only as a prefiguration of cinema, seen through its prism, overlooking it as an autonomous machine. Finally, in the very form of the machine drawn for the article, the fusion between Zoetrope and projector articulates a system of analogies common in the historiography of cinema as a whole.

\section{The Disc and the Strip}

One of them is epitomized by Georges Sadoul in the first volume of his 1946 Histoire générale du cinéma:

The Zoetrope is a new form of Plateau's slit disc [...]. The strip of images is its most remarkable aspect, for this long piece of flexible Bristol board prefigures film. The idea of indefinitely lengthening it certainly led Reynaud, and perhaps Marey and Edison, to conceiving modern film. ${ }^{14}$

The crucial historiographic idea here is the emphasis on an evolution: the Zoetrope was preceded by the Phenakistiscope, a device invented 
independently in $183^{2}$ by Belgian physicist Joseph Plateau and Simon von Stampfer. This toy - which for Sadoul literally made history, since its invention provided the starting point for his Histoire générale du cinéma - took the form of a disc. The disc was dark on one side; on the outer edge of the other, it featured a series of images representing the different stages of a decomposed movement alternating with a series of slits. With the eye placed on the dark side, looking through the slits at the images reflected in a mirror, the figures could be seen coming to life.

The principle is therefore the same - alternation between shutter and images through a system of regular slits allowing to produce the illusion of movement - but the medium changes from a disc to a strip: for Sadoul, this is the decisive point for what was to come, "modern film." These two toys did involve a few substantial differences, the main being that with the Zoetrope several spectators could see the phenomenon simultaneously, which was not the case with the Phenakistiscope. Yet this traditional history of optical toys, which sees progress running from the form of the disc to the form of the strip, then to film, calls for more complexity.

Indeed, the form of the disc did not disappear with the advent of the Zoetrope, as though the latter had made it manifestly "primitive": it long remained an alternative to the strip, as the list of a few devices relying on the principle of the disc shows: the Electrotachyscope, also invented by Anschütz, in the 188 os and 189os; the Phonoscope, by Étienne-Jules Marey's assistant Georges Demenÿ in 1892 (commercialized under the name Bioscope by Gaumont in November 1895); Leonard Ulrich Kamm's Kammatograph, on the market from 1898 to 1900; or the Spirograph, invented by Theodore Brown in 1907 and exploited by Charles Urban around the early 1920 s with a catalog worth several hundred titles... Finally, another, more recent medium should be mentioned: the DVD. Of course, it does not carry images in the same way as the previous examples (i.e., analogically), but its place in the series is still justified by ergonomic and industrial considerations. The disc as a medium is neither too fragile nor too cumbersome, relatively cheap to manufacture, and most of all easy to handle for the user - a decisive criterion for non-professionals, even more relevant in the case of mainstream users.

It should also be remembered that for Marcel Duchamp, thinking on (from, around, with) cinema, epitomized in his 1926 masterpiece Anemic Cinema, was part of a larger investigation around machinations of vision, the questioning of a tradition of monocular perspective, as well as discs and wheels of all kinds. 
I will not further develop this issue of the disc/strip alternative here. Let us just recall that it also structured the sound industry (including in movie theaters) and the music industry, the industry of computer and digital mediums, and that this alternative also carried economic, industrial, mechanical and aesthetic options. Still, the topos of the shift from disc to strip is one of the key points most strongly structuring the historiography of "pre-cinema," and will have to be revisited.

\section{With or Without Cranks}

At any rate, neither the Phenakistiscope nor the Zoetrope involved cranks, for the most part. We should dwell on this question of the crank a little more at this point, as it is more central than it may first seem. Some viewing dispositives contemporary with the two already cited did have these appendices: with the slides for "views set in motion," which spread from the mid-nineteenth century on, for instance, the crank made it possible to produce colored, abstract rosaces or to animate a specific part of a projected image. A remarkable example of optical machine using a crank was John Arthur Roebuck Rudge's magic lantern, manufactured around 1882, in which the crank drove the change of view, along with a shutter system, and through a triangular cam - supposedly a specific contribution of the Lumière brothers' own machine. Interestingly, when Will Day had a copy of this lantern made in 1922 (now held in the collections of the Cinémathèque française), the only license he took with the original was to move the crank from its initial position before the lens to a lateral position, probably more convenient in his view, and once again similar to that on a film projector.

Another fascinating machine comes to mind, even as it has been largely neglected by history, the Anorthoscope, the first optical device invented by Joseph Plateau before the Phenakistiscope. Through the combined movement of a black disc with slits rotating in one direction, and behind it, a disc with an anamorphic image rotating in the other direction, the device shows a corrected image when looked at against the light. It is fundamentally a crank-based machine, since the two discs have to be driven together and at correlative speeds. Fascinatingly, in his instructions for using the machine, Plateau did in fact recommend that the person turning the crank and the person observing the phenomenon not be one and the same. ${ }^{15}$

15 SeeJoseph Plateau 1801-1883. Leven tussen Kunst en Wetenschap, Vivre entre l'art et la science, Living between Art and Science, ed. Maurice Dorikens (Gent, Provincie Oost-Vlaaanderen, 2001). 
Looking at something being difficult work, two things could not be done seriously at once. Besides, Plateau was not just interested in optics, but also in the statics of liquids. In that field, he carried out an experiment that bears his name, founded on a machine that he had built and which was operated by a rotating crankshaft. Depending on the speed imparted by the experimenter/spectator, the form of the oil sphere in suspension in the water solution was transformed... ${ }^{16}$ The attention given to the crank as such re-establishes "Plateau's machine" among nineteenth-century viewing dispositives - a place it deserves considering that it was also relatively widespread, notably in schools, until the first quarter of the twentieth century. That the experiment was appreciated certainly had to do with its visual dimension - or should we say to its dimension of attraction? At any rate, the machine is completely absent from the entire historiography of these dispositives, massively written from the standpoint of "pre-cinema." And indeed, the form of the movement performed in this instance through these spheres in suspension radically differs from the medium to come: no two-dimensional images, no analytical sequence of decomposition/ recomposition, etc. This is what actually makes it interesting today within the perspective of an archaeological reconsideration of these machines outside any teleological linearity.

In fact, there had been crank-operated optical machines for a long time already, since some could be found in the first, 1646 edition of the famous Ars Magna Lucis et Umbrae by Father Athanasius Kircher: the "metamorphosis machine," for instance, in which the crank drove a series of images laid out on a cylinder running vertically (even though with Kircher, one can never be certain that the machines he described actually existed and that their effects conformed to the descriptions given...).

So, if almost no Phenakistiscope or Zoetrope had a crank, the crank must have been dispensable on these machines. Interestingly, there were not even "de luxe models" of these toys that would have used a crank, unlike what was to happen for the Praxinoscope a few years later.

\section{A New Form: The Praxinoscope}

The Praxinoscope (Fig. 3) was invented by Émile Reynaud and patented in 1877 , more than forty years after the Phenakistiscope and the Zoetrope, which were invented almost at the same time, and more than ten years 


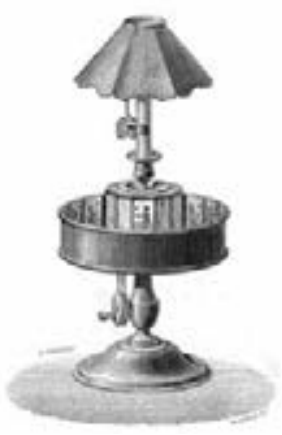

Fig. 3. Crank-operated Praxinoscope, La Nature 296 (February 1, 1879): 133.

after the Zoetrope was commercialized. The Praxinoscope has almost been confused with the Zoetrope by traditional historiography and presented as a relatively minor improvement on it. In truth, it seemed to be based on the same principles: a (horizontal!) cylinder and a series of drawings around it representing a decomposed movement, with the rotation of the cylinder showing spectators the image in movement. Yet the principle of the alternation of images was different: instead of slits, the machine presented a central block comprising a prism of mirrors with as many sides as there were drawings on the strip. The passage from one side to another instantaneously replaced the reflection of an image with that of another one in the same place, making the illusion possible. The idea was quite clever and accordingly constituted an important step.

Indeed, it solved an internal antagonism inherent in the Zoetrope and which also concerns the Phenakistiscope. An image continuously moving normally appears blurry and streaked. To appear sharp, it should be perceived as immobile by the eye. In that respect, the principle of rotation with slits causes a problem: the finer the slits, the more briefly the image appears to the eye (almost instantaneously in fact), and the more it is perceived as almost immobile and thus sharp, without streaks - a necessary condition in the reproduction of movement. But the more briefly the image appears to the eye, the less time the eye has to distinguish its outlines precisely and the less luminous the image is. In a way, the better the movement is seen, the worse the image is seen. This fundamental problem for the Zoetrope is repeated at another level: the faster the cylinder rotates, the briefer the perception of each image will be. As a consequence, the rendering of movement and luminosity, animation and the precision of outlines, find 
themselves in contradiction. Marey was in fact one of the few to describe this contradiction in his 1894 book Le Mouvement. ${ }^{17}$

Since the Praxinoscope did not require a shutter, the moving image produced was much more luminous and solved this contradiction to a large degree, even if minor flaws remained: the image was still slightly shorter due to a cylindrical anamorphosis, which Marey disliked, ${ }^{18}$ and it underwent a slight lateral oscillation caused by the rotation of mirrors. ${ }^{19}$ Still, the spectator could see a more luminous and sharper moving image more comfortably, and the speed of that image could be adjusted without consequences for the very visibility of the motif. This made it possible to improve the driving system of the machine so that the spectator could fully enjoy the spectacle - or, if you will, so that the handler could gradually become a spectator... While most Praxinoscopes remained hand-operated machines, some featuring a $\mathrm{crank}^{20}$ or even an electric engine could nonetheless be found. The advertising posters designed by Reynaud did in fact mention that these engines allowed a two-way rotation (though obviously the strips were meant to be seen in a specific way) as well as speed variation ${ }^{21}$ - in the latter case, the operation did not seem so simple.

This new luminosity was also to simplify the projection of images with the projecting Praxinoscope imagined by Reynaud as early as 1877 in the original patent, ${ }^{22}$ and whose illustration in the journal La Nature ${ }^{23}$ in 1882 (Fig. 4) proves very interesting: the screen is drawn, showing an image where moving characters and still setting have a different status, a distinctive aspect of the dispositive. The device is also shown, as well as

17 See Étienne-Jules Marey, Le Mouvement (Paris: G. Masson, 1894), notably p. 308: “as the sharpness of movements may be obtained only through the extreme brevity of instants in which each image is disclosed, the quantity of light emitted is accordingly too low to provide clear enlarged projections, even with a powerful source of light." Marey returns to this problem several times in the final chapter of the book on the "Synthesis of Movements Analyzed by Chronophotography."

18 Marey, Le Mouvement 303.

19 Indeed, before the passage from a mirror to the next replaces an image with the next one, the rotation of the prism causes a slight rotation effect for each image.

20 This is the case of the copy preserved by the Cinémathèque française under the classification mark AP-95-1720.

21 See Georg Füsslin, Optisches Spielzeug (Stuttgart: Füsslin Verlag, 1993) 92.

22 See the "Dessins annexés à la description d'une invention faite par E. Reynaud, professeur de sciences, au Puy, 30 août 1877," a document filed with the patent application, in Jacques Deslandes, Histoire comparée du cinéma, vol. 1, De la cinématique au cinématographe, 1826-1896 (Tournai: Casterman, 1966) 303 sqq.

23 Reproduced in Deslandes, Histoire comparée du cinéma 51. 


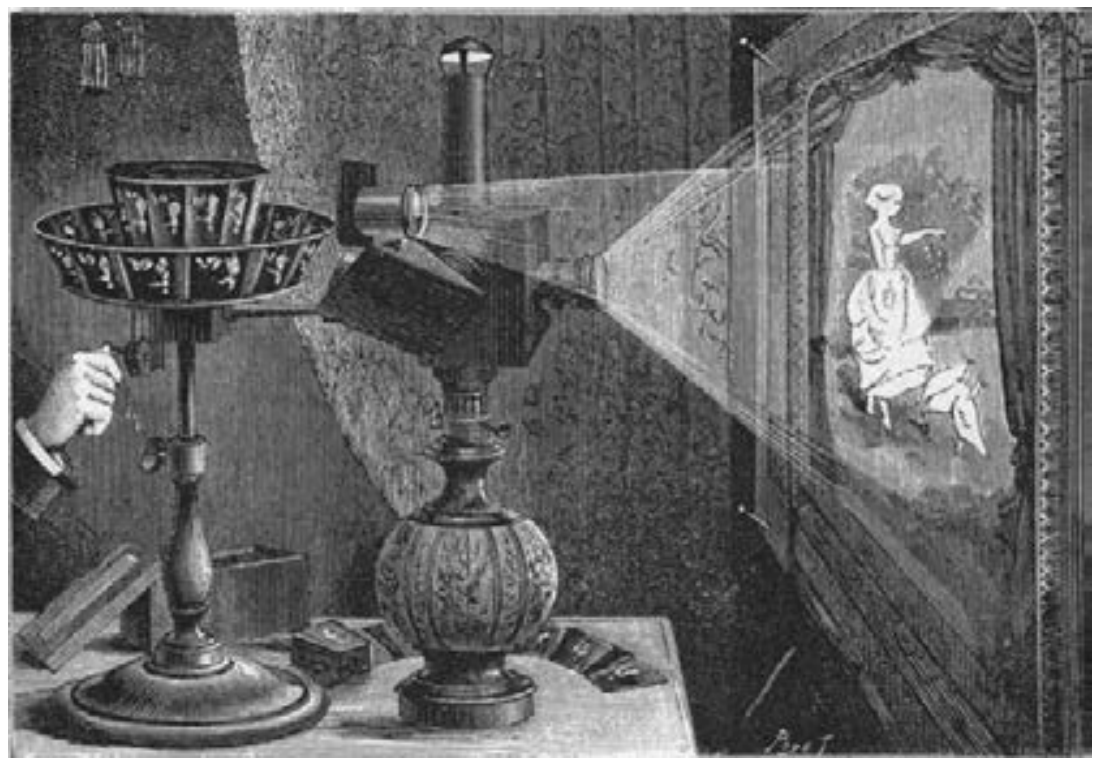

Fig. 4. Projecting Praxinoscope, La Nature 492 (November 4, 1882): 35.

a simple, fine hand elegantly turning a small crank near the edge of the frame; the bodies of the handler and spectator(s) are not represented in the image.

Other variants for the driving mechanism appeared in imitations of these objects, notably those made by Ernst Planck from Germany, sold around 1898 (which suggests that, two years after the success of the Cinématographe, the Praxinoscope could still prove attractive to a counterfeiter). Copies of what was called the Kinematofor remain - some with a crank, others with a steam engine or even a hot-air engine! ${ }^{24}$

The issue of luminosity was to play a decisive role in the first machines involving a moving photographic image: the dialectic was repeated in exactly the same way between Edison's Kinetoscope and the Lumière Cinématographe. The principle of the Kinetoscope was in fact similar to that of the Zoetrope: a strip moving continuously in front of which was a shutter with a very narrow slit (each image was seen for about 1/60oo sec.). As with the Zoetrope, the resulting moving image was too dark to allow projection. The Cinématographe solved this tension by adopting the intermittent movement of film for projection as well as for "the production of the negatives," as the Lumières put it. The image remained still a lot longer 
before the lamp (roughly $1 / 25 \mathrm{sec}$.), which produced more than enough light for the projection.

Interestingly, the Kinetoscope is not a crank-operated machine, which is the case for the Cinématographe.

\section{Cranks, Movement, Spectacle}

For the time being, however, let us return to Praxinoscopes. A majority of them did not come equipped with cranks, although a greater proportion of them did so than Zoetropes (even in the case of the Praxinoscopes produced by Émile Reynaud, which attests to a conceptual coherence on the part of the inventor). However, taking a closer look at these cranks as they appear and questioning their form (placement, size...) seems necessary. The cranks are placed under the cylinder, where they are the least in the way - the least visible, too (which is not insignificant). Also, with the "classical" Praxinoscope as well as the projecting machine, cranks are small and have a limited rotation diameter. Why do they have that shape? What, in the conception of a machine, may determine the addition of a crank and the choice of a form over another?

Cranks can fulfill several possible functions, sometimes simultaneously and, depending on the function, they can assume different forms. They prove necessary when there is a need for driving several elements at the same time, as in the Anorthoscope, or elements that can be heavy, as with Rudge's lantern. The same holds true when elements out of hand's reach have to be driven, as is the case again with some lanterns or with animated slides; when a very fast movement has to be produced, as in Newton's appliances for experiments on colors, which require a very quick rotation for the disc with colored areas to produce its effect and are thus equipped with a crank driving a belt; or when movement is to be controlled.

Small cranks do not allow an acceleration of the movement, be it through pulley differential or through a faster action of the arm or wrist. Turning such a small crank so quickly without causing the Praxinoscope to collapse must be very difficult. The point of using a crank is to control movement, rather, or even to slow it down, to make it possible to modulate rhythm, change directions, etc., within certain limits. The concrete form of the crank conditions a type of hand movement, which in turn points to a "good pace" for the movement to be produced, the scene to be represented - a "natural" speed, that of the drawn subject, whose own movement is broken down according to the motif. 
The presence of a crank does in fact completely transform the relation to the machine. Without it, the handler/spectator, once the disc or the strip has been set up, will start or restart the machine and possibly stop it. ${ }^{25}$ Between these punctual interventions, he is busy observing it. However, he cannot physically give a constant speed to the machine: rotation occurs only according to the inertia of the medium and therefore follows a "natural" slope, gradually slowing down... Only the presence of a crank permits real control over the rotation speed, if one that is relative in terms of precision. The counterpart is that the operator/spectator has to turn the crank for the whole show (or later, for the whole period of shooting with a camera). The form of the movement he sees is then no longer that of a slowing down characteristic of the machine, but the form of his own gesture: he can do his utmost to correct it until a perfect regularity is attained, or he can playfully alter it to observe the effects on the moving image or on fellow spectators. Indeed, while the Praxinoscope as a dispositive involves several spectators, one of them still has a particular status: the spectator operating the machine. The role is even more specific when a crank has to be turned...

Whether a crank is added to the machine or not thus effects a series of transformations in what is given to see and in the position of the spectator(s). A Zoetrope, a Praxinoscope without a crank are not so much machines presenting spectacles of moving images as they are machines setting images in motion. Starting and restarting the cylinder before slowly returning to immobility means that the cylinder always organizes the very animation of images and makes the machine operate like a comparative toy, between the series of still images to which it always returns and the ephemeral "moving tableau": transition is the point of the game.

As to the machines equipped with a crank, they present a spectacle with a given duration, determined by the handler, where not only the setting in motion, but also the prettiness of the scene, the subtlety of the drawing and the perfection of the execution can be admired.

On this point, in fact, the form of machines institutes yet another difference between Zoetrope and Praxinoscope. In the latter, the block of the central prism masks the strip as soon as it is placed in the cylinder: the image can then only be seen reflected in the mirrors. In the Zoetrope, by

25 Very interestingly, Werner Nekes, demonstrating the Praxinoscope in Was geschah wirklich zwischen den Bildern? ([Federal Republic of] Germany, 1986), the first film in his series Media Magica, shows not only the strips coming to life, but also the whole assembly of the toy - opening the box, placing the candle and, after a few other steps have been performed, the moment when moving images finally appear. This whole operation of assembling the machine should be considered as part of the dispositive. 
contrast, the strip can still be seen even when the cylinder rotates, until the eye is placed exactly at the level of a slit. The form of the Zoetrope therefore involves a comparative vertical movement (of the eye or the hand) between seeing the streak of the strip and seeing the moving image through a slit. In fact, another detail should be pointed out here, since an important difference between models of Zoetrope bears on this: Zoetropes with a low cylinder emphasize this comparative effect, while those with a higher cylinder tend to mask the strip to privilege a more important "effective" angle of vision. This vertical comparative movement is incompatible with the very form of the Praxinoscope.

Anschütz - again - was to take advantage of this vertical movement of the spectator's eye in an interesting model of his Tachyscope, whose cylinder featured three series of slits at different levels and slightly different intervals. In this way, if the strip represented a galloping horse, for instance, the viewer could see the animal move forward through the top row of slits, run without moving forward through the middle row of slits, and move backward through the bottom row... The model is also one of the very few Zoetropes with a crank and has another exceptional characteristic: it was owned by Étienne-Jules Marey. ${ }^{26}$

The whole issue of the relation between still and moving image is thus embodied in the choices made in the conception of the machines, the question of the presence of the elementary image in the moving image. This is also why filmmaker and artist Robert Breer, who early on became interested in the status of the film frame ${ }^{27}$ in his own films, ended up making Mutoscopes ${ }^{28}$ from the 1950 os on, sometimes with the assistance of Jean Tinguely... Essentially, the Mutoscope was an instrument with a crank thanks to which the spectator, fascinated but always physically active, could view the very composition given by the form of the gesture to animated movement. Indeed, while Gaumont initially commercialized its version of the Mutoscope in 1900 (one with a spring-loaded mechanism based on the Kinora patent registered by the Lumière brothers in 1896), the company soon opted for a crank-driven version... ${ }^{29}$

26 Cinémathèque française, collection of machines, inv. AP-95-1733. See Mannoni, Le Mouvement continué 270 .

27 Most notably in 1956-57 with what probably remains his most famous film, Récréation (16 $\mathrm{mm}$, color, $2 \mathrm{mn}$, commentary by Noel Burch).

28 See Robert Breer: Films, Floats \& Panoramas, Brigitte Liabeuf and Nathalie Roux, eds. (Montreuil: Éd. de l'œil, 2006) 48-49.

29 Gaumont produced "Kinoras à main," hand-held and crank-driven, until 1910 (the George Eastman House in Rochester, N.Y., owns a copy dated the same year by the G. E. House). 


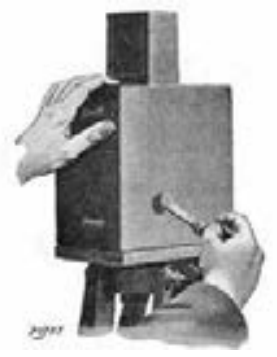

Fig. 5. Notice sur le Cinématographe Auguste et Louis Lumière (Lyon: Société anonyme des plaques et papiers photographiques A. Lumière et ses fils, 1897) 19.

Other artists were to produce their own versions of these optical machines, starting from very different principles and sometimes devising rather original driving solutions: the Mini Rotary Psycho Opticon, created in 2008 by Canadian artist Rodney Graham, gets its power from pedaling! $3^{\circ}$

As to motor-driven systems, they involve yet a different balance: on the one hand, with the possibility of a given duration at constant speed, they are comparable to crank-driven systems; on the other hand, the intervention of the handler remains punctual as the machine gets started and turned off, making their use quite similar to that of machines operated by hand...

\section{The Cinématographe, Art of the Crank}

The issue of driving mechanisms remained central after 1895 and constituted a common problem for all the optical machines involving movement, from optical toys to the cameras, projectors and flatbeds in a cinema on its way to cultural institutionalization and industrial rationalization. As I have already pointed out, the issue also represents one notable difference between Edison's machines, with their electrical engines, and the crank-operated Lumière Cinématographe (Fig.5). This should be related to differences in exhibition modes and target audiences: the Kinetoscope presented a spectacle while the Cinématographe was initially designed

30 This bicycle drives a series of abstract discs whose mechanism is reminiscent of Marey's odograph. It was presented during the exhibition $H F / R G$ [Harun Farocki/Rodney Graham], curated by Chantal Pontbriand, at the Jeu de Paume (Paris), April 7-June 7, 2009. It was unfortunately forbidden to operate the machine on that occasion... 
for the amateur photographer, unfazed by the crank and even likely to appreciate the subtleties involved in handling it.

Machines manufactured by competitors generally favored the crankdriven mechanism, and much effort went into finding the most suitable place and shape. German inventor Max Skladanowsky set the crank for his Bioskop at the front, under the shutter, which put the operator in the position of looking after the machine rather than at the screen. Louis Lumière positioned the crank of the Cinématographe at the back, slightly to the left of the device. This choice may first appear as rather inconvenient, but the machine has to be considered as a whole: the camera did not have a viewfinder and framing (like focusing) was set before shooting, with the camera open, looking through the printing gate. The film was then positioned, the camera closed back, and the operator stood while "cinematographing," looking directly at the subject. With this type of crank, the body was at a good distance from the camera: the cameraman was not "glued" to it. As far as I know, only the professional Pathé camera had its crank positioned at the back afterwards. Popular from 1908 on and into the 1920s, it was adopted by Billy Bitzer, D. W. Griffith's famous cameraman.

Englishmen Robert William Paul and Birt Acres placed their own crank on the side, a choice that later became the most common, and to the right, which allowed the body of the cameraman to come much closer to the machine, particularly after viewfinders appeared. In the end, it would hardly be an exaggeration to say that the history of cameras largely consisted in gradually "merging" the machine and the body of the cameraman... whereas the history of projectors and the disappearance of cranks from projecting booths, by contrast, were about allowing projectionists to move away from their machines, or exhibitors to have only one projectionist for several machines.

Of course, other options for the placement of the crank were sometimes adopted - under the machinery, for instance, and manipulated by three people in the case of Raoul Grimoin-Samson's panoramic Cineorama, in which ten cameras were driven simultaneously to cover a total field of 360 degrees.

Here as elsewhere, Étienne-Jules Marey appears to have been the exception: he did not like crank-driven mechanisms very much, privileging spring-loaded engines, weight engines or electrical engines, which ensured more precision and made possible a wider range of speeds and prompter starts. His machines sometimes had cranks, but these were meant to wind up the mechanism, not to drive it directly (Fig. 6). 

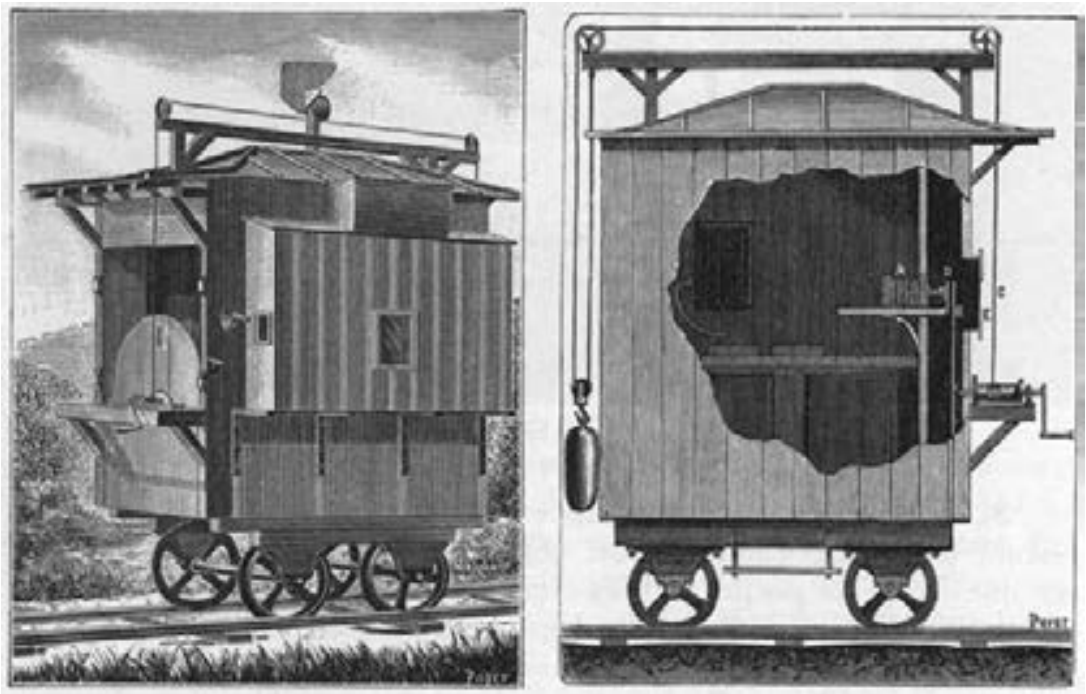

Fig. 6. Dark room on wheels with cameras inside, Étienne-Jules Marey, La Nature 535 (September 1, 1883) 229.

The driving system which was adopted sometimes brought about surprises: it so happened that the mechanism of the Lumière Cinématographe was one of the few to work backwards. This fact every operator, Louis Lumière being perhaps the first, was to discover as an unplanned oddity in the machine allowing for rather amusing games - a demolished wall rebuilding itself as if by magic, for instance..$^{31}$ The form of his machine thus led Lumière to leave behind the "paradigm of capture-rendering"32 that had apparently been the framework for his thinking until then.

The position and proportion of the crank ended up stabilizing. It remained the preferred mode for driving cameras and projectors for the entire so-called "silent" era until the late 1920s. A lot of questions obviously came up as to how it should be handled, emphasizing the tension inherent in

31 Démolition d'un mur is one of the views Louis Lumière credited himself in the catalog he gave Georges Sadoul in 1946. The destruction of a wall in the Lumière factory may be seen in the film, two versions of which are known today, dated early 1896 and numbered 690 and 691 in the catalog published by Michelle Aubert and Jean-Claude Seguin, where several quoted accounts confirm that they were frequently projected forward, then backward. See Michelle Aubert and Jean-Claude Seguin, La Production cinématographique des frères Lumière (Paris: Mémoires de cinéma, 1996) 215-16.

32 On this paradigm, see André Gaudreault, Cinéma et attraction. Pour une nouvelle histoire du cinématographe (Paris: CNRS éditions, 2008) 102 sqq. 
cinema between the theoretical reversibility camera-projector and the actual asymmetry orienting each practice and each machine differently - a tension already very strong with Marey ${ }^{33}$ Manuals and directions for movie cameras insisted on the difficult and unfairly derided art of the crank, the absolute need for regularity, whether a turtle or a horse race, a funeral or a ball were being filmed. The art was all the more tricky as camera tripods were soon to allow panoramic and tilting movements thanks to... two additional cranks. A cameraman thus needed three hands, which created a few problems solved here and there through a more or less cumbersome human or electric assistance... This art of the crank demanded, for instance, that the machine be occasionally weighted so as to add stability to it, an aspect already considered in the directions for the Lumière Cinématographe in 1897: the crank had to be turned, "making sure to hold the appliance firmly with the left hand, pressing on the stand to avoid vibrations. ${ }^{34}$ In this one case, the legendary lightness of the Lumière machine backfired...

Manuals for projectionists also highlighted regularity for the "naturalness" of the movement, but kept the door open to speed variations, sometimes even suggesting them to "expressive" ends. The degree of subversion of Dziga Vertov's 1923 statement can be grasped only when this distinction between shooting and projecting is maintained:

Until now many a cameraman has been criticized for having filmed a running horse moving with unnatural slowness on the screen (rapid cranking of the camera) - or for the opposite, a tractor plowing a field too swiftly (slow cranking of the camera), and the like.

These are chance occurrences, of course, but we are preparing a system, a deliberate system of such occurrences, a system of seeming irregularities to investigate and organize phenomena. ${ }^{35}$

In this textual "montage," Vertov amusingly combines the Muybridgian topos of the galloping horse with the agricultural mechanization so crucial for the USSR - through the action of his crank, he reverses the traditional association of speed with the horse and slowness with the tractor, giving a more politically "progressive" version of it. If the film industry on its way to

34 Notice sur le Cinématographe Auguste et Louis Lumière (Lyons: Société anonyme des plaques et papiers photographiques A. Lumière et ses fils, 1897) 19.

35 "The Council of Three" (1923), in Kino-Eye. The Writings of Dziga Vertov, Annette Michelson, ed., trans. Kevin O’Brien (Berkeley, Los Angeles: University of California Press, 1984) 15-16. 
institutionalization banned these speed variations during shooting, it was also because it was impossible to correct them: no speed variation during projection - or in the laboratory - could produce a "natural" movement if the shooting speed had been too high. This kind of power, with the explosive political potential expressed by Vertov here, could not possibly be granted to cameramen.

The crank allowed even more than speed variations: it did not require any settings to be chosen beforehand, nor did it involve a "default" pace. It also made the machine reactive and autonomous, independently of available electricity outlets. The electrical motor became generalized when the advent of synchronized sound imposed a constant, automatic pace of 24 images/sec. This resistance of cameramen to electrification had to do with the "margin of indeterminacy" which, according to Gilbert Simondon, gave a machine its real value, as opposed to automatism:

Idolators of the machine generally assume that the degree of perfection of a machine is directly proportional to the degree of automatism. [...] Now, in fact, automatism is a fairly low degree of technical perfection. In order to make a machine automatic, it is necessary to sacrifice many of its functional possibilities and many of its possible uses. Automatism [...] has an economic or social, rather than a technical, significance. ${ }^{36}$

\section{The Presence of Machines}

Observing machines in detail, taking into account their uses, the discourses concerning them, but also their forms, does not necessarily lead to stress the continuity of an abstract principle - the production of an illusion of movement out of a series of still images - over time. Rather, it means identifying as precisely as possible the conditions of perception produced specifically by each machine, and discovering discontinuities between concrete viewing situations, between forms of movement which these machines make visible. From Phenakistiscopes to Zoetropes, from Zoetropes to Praxinoscopes, from models using a crank to models dispensing with it, featuring an electric engine or a spring-loaded engine, a wide or narrow cylinder, the diversity of machines materializes divergences in the conception of what it is to see 
a moving image. These divergences should not be brought to a resolution or even too linearized if the protean wealth of the medium(s) examined is to be grasped, and the theoretical, historiographic and epistemological consequences are to be assessed. This dismissal of linearization should lead us to take into account marginal processes and practices as well as dominant ones, Anschütz (to whom this contribution is a homage of sorts, in the end) as well as Lumière, because their existence, like their marginality with respect to the industry, may give us a better understanding of the history of the medium - machines, perception, art.

However, research on machines also involves another, parallel level. American poet Williams Carlos Williams wrote in 1944:

To make two bold statements: There's nothing sentimental about a machine, and: A poem is a small (or large) machine made of words. When I say there's nothing sentimental about a poem I mean that there can be no part, as in any other machine, that is redundant. [...] As in all machines its movement is intrinsic, undulant, a physical more than a literary character. In a poem this movement is distinguished in each case by the character of the speech from which it arises. ${ }^{37}$

In 1944 these paragraphs summed up the contribution of the most radical side of American poetic modernity, in a way. To approach a work of art as a machine has rather important implications for its analysis, for considering the place of its reader or spectator, and quite simply for understanding what is at stake for us in the experience of its form. 